
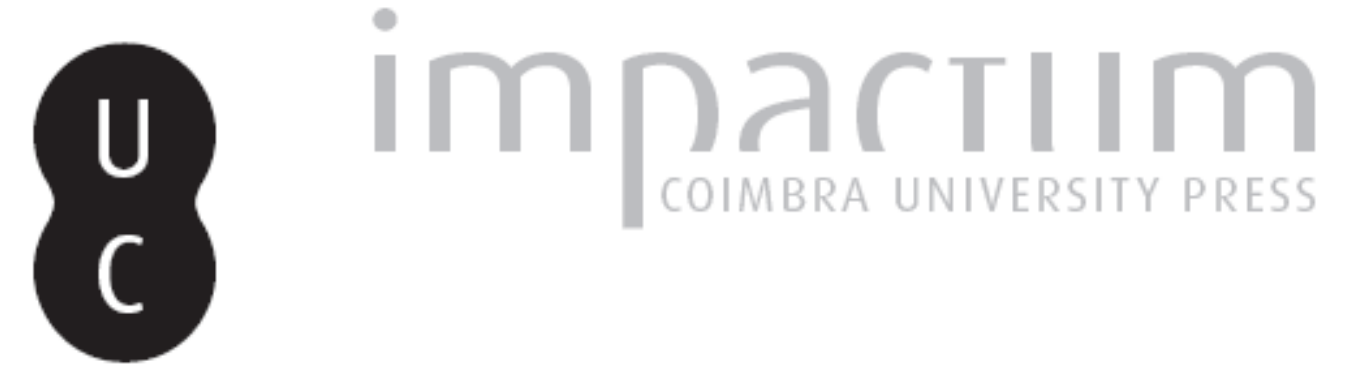

\title{
Stress ou burnout dos profissionais de segurança
}

Autor(es): $\quad$ Rebelo, Joaquim; Leal, Joaquim

Publicado por: Associação Portuguesa de Riscos, Prevenção e Segurança

URL persistente:

URI:http://hdl.handle.net/10316.2/36024

DOI:

DOI:http://dx.doi.org/10.14195/1647-7723_19_25

Accessed : $\quad$ 26-Apr-2023 10:51:04

A navegação consulta e descarregamento dos títulos inseridos nas Bibliotecas Digitais UC Digitalis, UC Pombalina e UC Impactum, pressupõem a aceitação plena e sem reservas dos Termos e Condições de Uso destas Bibliotecas Digitais, disponíveis em https://digitalis.uc.pt/pt-pt/termos.

Conforme exposto nos referidos Termos e Condições de Uso, o descarregamento de títulos de acesso restrito requer uma licença válida de autorização devendo o utilizador aceder ao(s) documento(s) a partir de um endereço de IP da instituição detentora da supramencionada licença.

Ao utilizador é apenas permitido o descarregamento para uso pessoal, pelo que o emprego do(s) título(s) descarregado(s) para outro fim, designadamente comercial, carece de autorização do respetivo autor ou editor da obra.

Na medida em que todas as obras da UC Digitalis se encontram protegidas pelo Código do Direito de Autor e Direitos Conexos e demais legislação aplicável, toda a cópia, parcial ou total, deste documento, nos casos em que é legalmente admitida, deverá conter ou fazer-se acompanhar por este aviso.

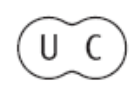




\section{territorium}

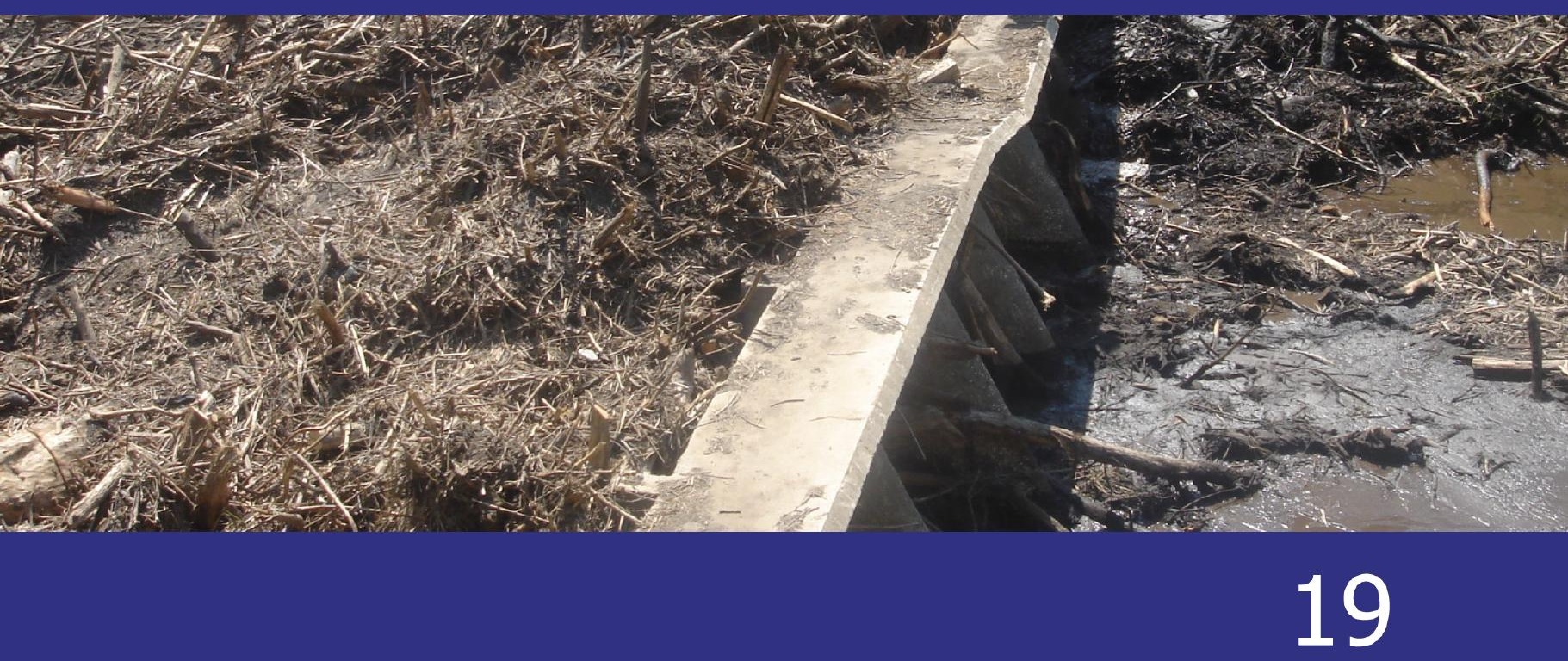

\section{Reequacionar o Conhecimento dos Riscos e das Catástrofes}

Revista da Associação Portuguesa de Riscos, Prevenção e Segurança 


\section{NOTAS, NOTÍCIAS E RECENSÕES}

Joaquim Rebelo

Instituto Superior das Ciências da Informação e da Administração joaquimrebelo19@hotmail.com

Joaquim Leal

Instituto Superior das Ciências da Informação e da Administração joaquimleal@netvisao.com

\section{Introdução}

O Homem surgiu no planeta Terra há poucos milhões de anos e segundo os factos históricos, o Ser Humano limitava-se a satisfazer as necessidades básicas, tais como caçar para comer e procriar. Com o decorrer dos anos e com o constante aumento da população e escassez de alimentos, o Ser Humano passou a dedicarse à agricultura, criação e pesca. Como é perceptível a esperança média de vida era curta, os conflitos entre clãs eram causados pela luta pelos recursos e as doenças eram imensas, mas todas de carácter físico, não psíquico.

As primeiras épocas para o Homem foram de exploração terrestre, conquista de território e posteriormente a sua fixação. O Ser Humano é dotado de uma característica que é a insatisfação que consequentemente leva à inovação. O Homem desde sempre procurou ir mais além, e assim surgiu a máquina a vapor.

Só com a revolução industrial e com o aparecimento das indústrias é que surgiram as doenças psíquicas associadas à laboração, são elas a depressão, o esgotamento, o stress... Por isso o stress pode-se considerar como um problema de carácter psíquico, que surgiu no século XX e que afecta principalmente as sociedades industrializadas.

\section{Stress/burnout - definição e causas}

Deve-se inicialmente procurar uma definição para a palavra que é o tema deste trabalho (Stress), para posteriormente se desvendar as suas causas e as consequências. O INSTITUTO NACIONAL DE SAÚDE E SEGURANÇA OCUPACIONAL (NIOSH) define o "stress de trabalho" como as respostas nocivas físicas e emocionais que ocorrem quando os requerimentos de um emprego, não se alinham com o nível de habilidade, recursos ou necessidades do trabalhador. Uma outra fonte define como: "resposta física ou psico-física, generalizada e não especifica do nosso organismo face a determinadas condições externas, sendo resultante da nossa interacção com o meio envolvente". Mas muito sucintamente, é um estado que se caracteriza por elevados índices de excitação e angustia, com sensação de impotência. É uma qualquer interferência que perturbe o bem-estar mental e físico de um indivíduo.

Quanto ao Burnout que também se integra e "relaciona" com o stress, define-se como uma resposta prolongada no tempo, a elementos stressores interpessoais, crónicos no trabalho, constituído por três dimensões/medidas "chave": exaustão emocional, despersonalização e redução da realização pessoal. 0 Burnout deve ser considerado um prolongamento do stress ocupacional, sendo o resultado de um processo de longa duração, em que o profissional sente que os seus recursos para lidar com as exigências colocadas pela situação já estão esgotados.

Como o título do trabalho indica, este trabalho é específico ao stress ou Burnout dos profissionais de segurança.

\section{As causas do stress}

O stress no trabalho pode ser causado por diversos factores físicos e psicossociais.

Os factores psicossociais, são de certo os mais importantes na causa do stress, porque são gerados pelo cariz da organização institucional. Se a nível institucional, a exigência é muita, esta acresce ao controlo dos profissionais o que resulta num desgaste psico-emocional (fot.1).

Com a imposição dos novos estatutos nas forças de segurança, os profissionais da Polícia de Segurança Pública (PSP) e Guarda Nacional Republicana (GNR), 


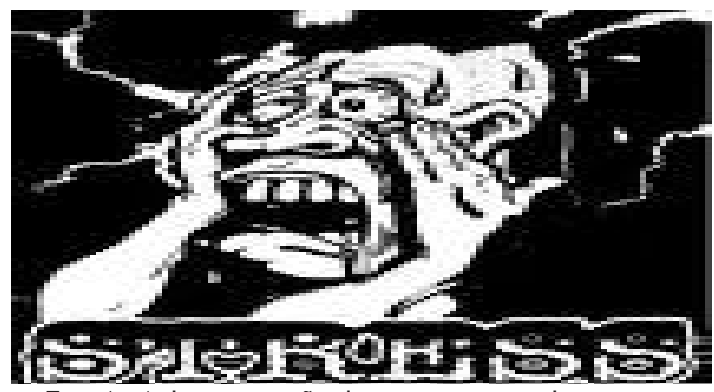

Fot. 1 - A demonstração de como o stress desgasta as pessoas.

passaram a ter um modelo de avaliação, simétrico aos funcionários públicos e consequentemente, os aumentos remuneratórios são efectuados com base na classificação obtida. Se anteriormente as palavras mais escutadas nos postos e esquadras nacionais eram cooperação e união, estas tender-se-ão a desvanecer. Isto porque a atitude do militar/polícia altera com a imposição de novas regras.

Estas alterações fizeram com que os elementos das forças de segurança passassem a ser mais individualistas, porque o que evidencia um elemento dos outros, aos "olhos" de um superior hierárquico é: o número de autos elaborados, o guardar de informações para si próprio a fim de se sobrepor como melhor elemento, o denunciar dos erros dos camaradas...

Quanto aos factores físicos, evidencia-se o excesso da carga horária (um dos lemas das instituições é que se é polícia 24 horas por dia), que pode superar as noventa horas semanais. Ser-se polícia é um ofício de turnos, onde todos os dias se trabalha em horas diferentes. Esmiuçando um pouco esta situação e para se dar a conhecer a realidade de um elemento das forças de segurança: um polícia de serviço da meianoite até as oito da manhã e que tenha presenciado um crime, por exemplo de um indivíduo com álcool no exercício de condução, tem de elaborar o expediente para o ministério público (auto de notícia, constituir o condutor de arguido....) e depois do serviço, tem de se apresentar no tribunal pela manhã, na qualidade de agente autuante do processo. 0 que inicialmente seria um turno de oito horas, passou a ser de 12 a 16 horas, mas falta mencionar um pormenor interessante, o elemento das forças de segurança devia de estar a descansar, porque muito possivelmente o seu serviço é novamente da meia-noite às oito.

\section{O elemento das forças de segurança é uma pessoa sem vida própria}

A sociedade em geral, tem por hábito associar aos elementos das forças de segurança, uma actividade profissional pouco agastada tanto física como psiquicamente, isto é, em termos corriqueiros apelidar os agentes de "calões" ou "malandros". Isto demonstra um total desconhecimento dos factos, porque o elemento das forças de segurança tem de ser multifacetado. Isto é demonstrável na postura irrepreensível, na qualidade de bem-falante, no transcrever dos factos observados para expediente enviado para as mais diversas entidades (normalmente para o ministério publico), ser-se conhecedor da lei, muito genericamente o polícia tem de ser uma pessoa exímia. Como se tal não fosse suficiente, tem de acrescentar outros factores, e estes com uma vertente diferente e com índice de dificuldade acrescido, são eles: a falta de elementos, o trabalhar por turnos, o excesso da carga horária, o afastamento da família e da terra natal, a falta das folgas e horas de descanso, um ambiente profissional de cariz militar, a prepotência das chefias... Atendendo aos factos descritos, não faltam motivos de stress para um ofício que requer tanto sacrifício e espírito de corpo.

Como anteriormente descrito, as esquadras e postos do território nacional eram os locais de exemplo de cooperação e espírito de camaradagem. Eram, porque o novo sistema de avaliação vem implicar a alteração do comportamento e atitudes de alguns elementos das forças de segurança. O elemento das forças de segurança é um indivíduo nómada, isto porque anda durante os seus anos de serviço de malas às costas. Fazendo-se uma resenha, um indivíduo que seja do Norte do país, e que inicie a sua actividade profissional na GNR ou PSP, começa por ter aproximadamente um ano de formação. Posteriormente, é colocado na Grande Lisboa ou Algarve, porque são os locais com falta de efectivo e maior concentração populacional, efectuado o pedido de transferência para perto de casa, este demora na GNR aproximadamente dois anos para os militares de infantaria e sete anos para os de cavalaria, na PSP a espera é em média de dez anos. Acrescendo ainda que na GNR, sempre que o militar é promovido, é recolocado na zona sul do país, isto porque no seio destas instituições, a maioria dos elementos são do norte do país.

Como é perceptível, não há condições para que os elementos das forças de segurança, possam ter uma vida conjugal e constituir família, até se estabelecerem. Para ocorrerem estas condições, têm de abdicar de uma carreira de progressão profissional em prol da família. Este ofício, atendendo as características descritas, tem mais susceptibilidade da causa de stress, quando comparável com outros.

\section{Sinais de stress}

O stress pode-se evidenciar de bastantes formas, mas só numa primeira fase é perceptível pela pessoa que por ele se vê afectado. Porque posteriormente com o desgaste psicológico, o lesado não descortina a situação em que se encontra envolvido. 
Os sinais avançados que podem avisar a presença de stress podem incluir os seguintes sintomas físicos: dores de cabeça, irritações de pele, distúrbios do sono, problemas de estômago/intestinos...

Quanto aos sintomas psicológicos são: esquecimento, irritação, cansaço, depressão, ansiedade, falta de forças...

\section{Como os elementos de segurança reagem em situação} de stress

O Homem como ser individual, manifesta o seu agrado e desagrado das mais diversas formas. Como é sabido, ninguém é igual a ninguém e como tal, cada pessoa tem a sua forma de reagir.

É característico do Ser Humano, nunca admitir um problema que o afecte. Como tal, os casos de stress são a maioria das vezes detectados pelos colegas de trabalho, porque são as pessoas mais próximas e que mais convivem com a pessoa afectada. São as atitudes diferentes e as formas de reagir que indiciam a situação de stress. Mas nem sempre tudo é perceptível, porque existem postos e esquadras de grande efectivo e o companheiro de serviço nunca é o mesmo, como tal ninguém conhece na íntegra a personalidade de ninguém e os casos de stress e Burnout passam facilmente descaracterizados como uma má disposição psíquica, de uma noite mal dormida.

\section{A solidão como o primeiro passo para o álcool}

Um fenómeno muito comum e associado aos elementos das forças e segurança é o alcoolismo. No seio da GNR já existe um centro de tratamento e acompanhamento, para os militares que se refugiam no álcool. 0 álcool surge como um "escape" para os elementos das forças de segurança que se vêem afastados do seu lar e por vezes em processos de divórcio.

Um grande problema, na actividade profissional dos elementos das forças de segurança, é alistar-se com o estado civil de casado. A data limite de entrada para as forças de segurança é de vinte seis anos, para pessoas que não estejam nas forças armadas. Como há algumas décadas o casamento era no fim da adolescência, a maioria dos elementos eram casados. Na actualidade os números são diferentes, mas é comum haver em cada alistamento um número significativo de elementos casados e com filhos. Atendendo às condições de colocação anteriormente descritas, e às folgas que dentro dos parâmetros normais são ao oitavo dia de serviço de um dia de folga, muito dificilmente qualquer casamento resiste. Os problemas $e$ desavenças familiares mais tarde ou mais cedo surgem, e atendendo a que ninguém gosta de expor os seus problemas o que para muitas pessoas é dar parte de fraco, o elemento policial encontra refúgio nas bebidas alcoólicas (fot.2). Como é perceptível todas as pessoas reagem de diferentes formas, e o álcool é mais uma condicionante do stress.

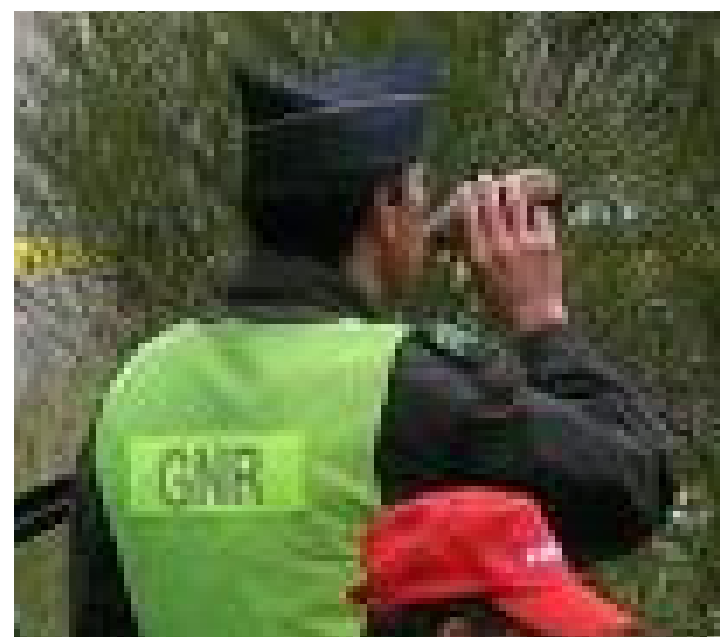

Fot. 2 - Álcool - refúgio para os profissionais das forças de segurança.

As missões de restabelecimento de paz como factor de stress

É bastante comum a Guarda Nacional Republicana estar envolvida em missões de restabelecimento de paz, das quais se destaca: Timor, Iraque e Kosovo. Os efectivos envolvidos nestas missões são normalmente das unidades de reserva Regimento de Infantaria, na qual se inclui a Companhia de Operações Especiais (fot.3) e do Regimento de Cavalaria. Também por vezes, e só nas missões de salvamento, há a envolvência de equipas de binómio Homem-Cão (Cinotécnica). As missões podem durar anos, mas os mesmos elementos ficam por um período que oscila entre os seis meses e um ano. Para estes elementos envolvidos nas missões, há dois factores de elevado grau de stress, que são o teatro de operações e o factor distância.

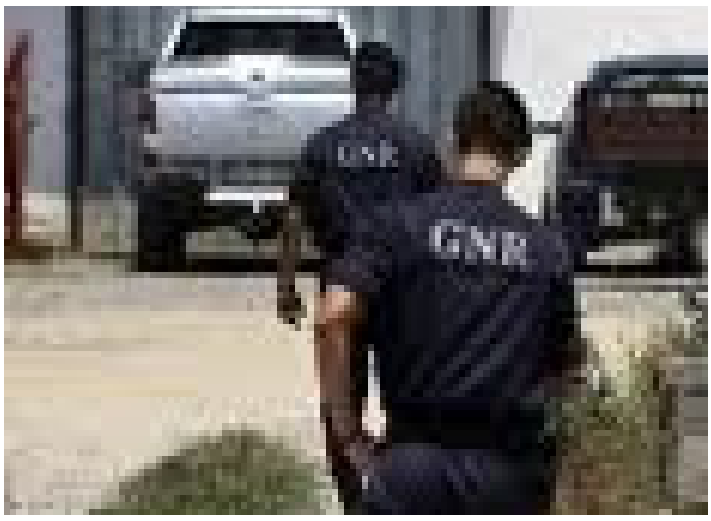

Fot. 3 - Unidade em missão de restabelecimento de paz.

É de conhecimento geral, que os elementos envolvidos em missões são todos voluntários, mas há por "detrás" agentes/condições que influenciam a disposição/ vontade de um indivíduo. São estas, as condicionantes monetárias e a de carreira profissional. É de salientar que a maioria dos elementos envolvidos está em início de 
carreira, porque está em unidades que são de colocação de fim de curso (início de carreira). Estas unidades estão preparadas para intervir em situações de missão no estrangeiro ou de restabelecimento de ordem pública em território nacional; como tal, o efectivo necessita de formação regular (preparação física, tiro...), o que demonstra ser para gente jovem.

Aprofundando os dois grandes factores de stress nas missões de paz:

-O teatro de operações tem sempre características próprias e por muito que se idealize, a realidade é sempre outra. É um clima que se classifica como tenso, em que o risco é o acompanhamento permanente e como se sabe, a tensão acompanha o stress. Para os militares das forças de segurança, o terreno é desconhecido, e para aquele povo estes elementos não passam de seres invasores. Depois, como o clima é de conflito e é frequente o detonar de bombas e a troca de tiros, por vezes o alvo voluntário ou involuntário, pode ser as equipas de restabelecimento de paz.

Para se fazer parte integrante em missões deste género, é necessário saber trabalhar em equipa; é o lema que se designa " um por todos e todos por um", porque basta descurar um controlo, para se pôr todo e efectivo em risco.

-Quanto à distância, não há forma de minimizar, porque se as novas tecnologias são um "encurtar" de distâncias, essa nunca se pode reduzir na totalidade. Isto quando há possibilidade de comunicação, porque a maior parte das vezes, as comunicações são cortadas ou são única e exclusivamente para uso das diversas forças envolvidas na missão.

Há também uma outra característica que se associa aos locais de missão: são sempre em países subdesenvolvidos e como tal há imensas restrições, quer de carácter tecnológico quer social.

\section{O suicídio nas forças de segurança}

O Homem é um ser social e como tal necessita de viver em sociedade, isto traduz-se na necessidade de conviver, dialogar...com outras pessoas. Com o afastamento dos mais próximos e com o degradar do estado físico e psíquico, o Ser Humano tem tendência a isolar-se. 0 isolamento é mais um factor negativo, porque a "carga" psicológica "acumulada" agrava o mau estar, e é nestas circunstâncias que mais se necessita de dialogar e consequentemente de se ser apoiado.

$\mathrm{Na}$ actualidade, as forças de segurança em Portugal têm psicólogos no seu corpo de efectivos. Estes estão à disposição de todos, mas o problema é que quem necessita deste apoio, não o procura. Por isso, cabe a todos o diagnosticar de situações, porque aparentemente os colegas/camaradas de trabalho não se encontram no seu perfeito bem-estar físico, psíquico ou emocional, muito possivelmente estão em stress e necessitam de apoio.

Quando não há nos profissionais das forças de segurança a delicadeza de saber se o colega necessita de apoio, acabam por presenciar a mortandade de alguém conhecido. A maioria dos polícias em Portugal acaba por pôr termo à vida (suicídio) sem que qualquer colega de profissão detecte qualquer indício que o fizesse prever. Isto só acontece porque há imenso trabalho e porque o tempo de descanso/lazer não é tanto quanto o necessário. Também o aparecimento da Internet proporcionou a que as horas de ócio passassem a ser ocupadas nas redes sociais, o que anteriormente era feito em convívio.

Assim, os psicólogos passam a ter uma outra tarefa, que não é a de prevenção de um suicídio mas a de prestar apoio à família da vítima.

\section{O suicídio no local de trabalho}

"Um suicídio no trabalho é uma mensagem brutal" é o título da notícia de um jornal diário, aquando de uma conferência proferida pelo psiquiatra, psicanalista e professor Christophe DEJOURS em Lisboa no primeiro trimestre do ano de 2010. Para este médico e escritor francês para o suicídio ocorrer no local de laboração, existe uma mensagem escondida neste acto.

Deve-se inicialmente desvendar as causas, para posteriormente se efectuar uma análise e assim desvendar a mensagem.

Para o(s) autor(es) deste trabalho, a escolha do local de laboração para o suicídio, é uma forma de demonstração de descontentamento para com o sistema de funcionamento da instituição, porque qualquer elemento é tratado como um número e não com a dignidade de um Ser Humano. Para um profissional de segurança, a instituição que representa tem uma cota parte na destruição de casamentos/lares e na falta de qualidade de vida. As instituições querem que todos os seus elementos tenham espírito de abnegação e de corpo, em detrimento de uma vida própria.

\section{Período de convalescença}

Quando os casos de stress são detectados nos profissionais das forças de segurança, resulta em redução no efectivo, devido ao período de convalescença (baixa). Um grande problema nacional (Portugal) é o restrito número de elementos que constituem o corpo da PSP e GNR. É frequente observar nas notícias, os presidentes de câmara de diversos munícipes, solicitarem o reforço de polícias nos Postos e Esquadras. A questão que se formula é a seguinte: Qual a razão para a falta de polícias? 
A resposta é dada pelas políticas impostas pelos governos, mais especificamente pelo Ministério da Administração Interna.

Este problema da falta de elementos, é proveniente da relação do número de polícias que se reformam com o número de novos cadetes e guardas que se formam anualmente. Uma das políticas do anterior Ministro da Administração Interna (António Costa) era a redução no número de formandos na polícia e consequentemente nas vagas disponíveis para os cursos.

Atendendo às frequentes queixas escutadas nos órgãos de comunicação social, coube ao governo a imposição do alargamento da idade da reforma. Mas esta solução só traria "frutos" (resultado) a longo prazo, então atendendo à circunstância, houve necessidade de alargar o número de vagas por curso.

\section{Falta de efectivos}

Mas o ingresso de um número equivalente de militares, não é suficiente, porque nos dias de hoje há muitas mais especializações dentro das instituições policiais, o que origina num número cada vez mais restrito de polícias nos postos e esquadras.

Fazendo um retrato da GNR, na actualidade existe: Unidade de Acção Fiscal, Unidade Nacional de Trânsito, Unidade de Controlo Costeiro, Comando Geral (acrescido os Serviços Sociais e Centro Clínico), Unidade Intervenção (no qual se inclui a Companhia de Operações Especiais, Corpo de Restabelecimento de Ordem Pública, Companhia Cinotécnica e a Inactivação de Engenhos Explosivos Improvisados), Unidade de Serviços e Honras de Estado (Regimento de Cavalaria) e os Comandos Territoriais (Postos, Núcleo de Investigação Criminal e Núcleo de Apoio Técnico e Serviço Especifico de Protecção da Natureza e Ambiente).

Esta ramificação é resultado de uma evolução paralela, entre a GNR e as necessidades dos dias de hoje. A consequência desta evolução resulta na falta de efectivos nos postos territoriais. É de extrema importância realçar que a grande maioria de casos de stress ocorrem nos Postos Territoriais e a razão é o excesso de carga laboral.

Mas é também importante referir, que num universo de aproximadamente vinte sete mil elementos, que são o total de efectivos da GNR, só a nível administrativo o número é superior a seis mil. Atendendo à ramificação da GNR, estima-se que nos oitocentos postos territoriais o número de efectivos seja inferior a quinze mil, o que demonstra a carência nacional de elementos policiais para reforço dos postos, já que estes são os únicos afectados na falta de efectivos.

\section{O stress como um problema global}

O stress é um problema dito global porque envolve todas as nações, mas com especial incidência nos países industrializados. Atendendo às estatísticas a nível dos países membros da União Europeia, estima-se que o stress afecte um número superior a 41 milhões de trabalhadores. Estes dados, traduzidos em números de dias de ausência do profissional no local de trabalho, dá uma ideia dos valores económicos de prejuízo causados pelo stress.

Como tal, a Comissão Europeia procedeu à introdução de medidas que assegurem a segurança e a saúde dos trabalhadores com a finalidade de reduzir as despesas causadas pelo período de convalescença do profissional.

A nível das forças de segurança, foram tomadas algumas medidas, tais como: provas psicotécnicas e entrevista com um psicólogo como prova de acesso, inserção no corpo clínico de psicólogos, uma linha telefónica de apoio. Mas o resultado prático foi nulo, porque o número de suicídios é crescente, e acompanhando esta taxa, a entrada de profissionais para consultas de apoio psicológico também aumentou.

\section{Conclusão}

As actividades profissionais devem ter como principal característica o dinamismo, razão pela qual nos anúncios de trabalho um dos requisitos é ser dinâmico. É também sabido que a tensão pode melhorar o desempenho dos profissionais e assim proporcionar a satisfação dos superiores hierárquicos, por isso a tensão e o dinamismo são importantes quando se procura atingir objectivos. Como é óbvio, a acção está associada ao stress, logo quase todos os ofícios/empregos não podem estar dissociados do stress. Atendendo a estas circunstâncias pode-se dizer que um pouco de stress é necessário, mas não intensivo, consecutivo ou repetido em que a pessoa não possa lidar/aguentar. Porque tudo o que é em excesso é prejudicial, e neste caso o stress faz com que ocorra desordens psicológicas ou doenças físicas.

QUADRo I - Elaborado com base nos dados facultados pelo gabinete de psicologia da GNR.

\begin{tabular}{|c|c|c|c|c|}
\hline \multirow{2}{*}{$\begin{array}{c}\text { Número de suicídios } \\
\text { (média) }\end{array}$} & \multicolumn{3}{|c|}{ Taxa dos que se suicidaram e que tinham } \\
\cline { 2 - 4 } & $\begin{array}{c}\text { Mau relacionamento } \\
\text { familiar }\end{array}$ & $\begin{array}{c}\text { Problemas com o } \\
\text { álcool }\end{array}$ & $\begin{array}{c}\text { Mudado de estilo } \\
\text { de vida }\end{array}$ & Perdido familiares \\
\hline Até 2006 é de 2 & $56 \%$ & $56 \%$ & $78 \%$ & $57 \%$ \\
\hline 2008 é de 10 & $56 \%$ & $56 \%$ & $78 \%$ & $57 \%$ \\
\hline
\end{tabular}


Em qualquer ofício, o stress é sentido pelos funcionários, quando as exigências colocadas pelo ambiente de trabalho excedem a capacidade de suportação dos trabalhadores, por isso cabe às entidades patronais o regular e avaliar da situação.

Como interpretado no corpo do texto, o stress pode acarretar tanto problemas de carácter físico como problemas de carácter psíquico. Por isso, é importante mencionar as consequências ou problemas associados ao stress: depressão, ansiedade, nervosismo, fadiga, problemas cardíacos e em casos extremos o suicídio.

Ao nível profissional o stress reflecte-se na produtividade, na falta de vontade ou desmotivação, no desinteresse profissional, na alteração de atitudes e estilo de vida, no descuido e no brio da apresentação...

Quanto a nível social o elemento afectado pelo stress vê-se privado na conquista de novos amigos, porque as condições emocionais não proporcionam o dialogar mas sim o isolamento. Quanto ao núcleo de amigos, conhecidos e familiares, estes tender-se-ão a afastar-se.

Atendendo a que o bem-estar físico, psíquico e mental é uma das preocupações nos países desenvolvidos, a Comissão Europeia introduziu medidas que asseguram a segurança e saúde dos trabalhadores a nível europeu de qualquer sector de actividade. A Directiva de 1989 do Conselho (89/391/CEE) contém as disposições básicas em matéria de saúde e segurança no trabalho, e torna as entidades patronais responsáveis por assegurar que os trabalhadores não sejam prejudicados pelo trabalho, nomeadamente pelos efeitos do stress. Assim todos os Estados-Membros aplicaram a mencionada directiva através de legislação apropriada, tendo alguns desenvolvido também linhas de orientação que visam a prevenção do stress no trabalho.

Como o stress é aliado do suicídio e com o aumento destes casos na PSP e GNR, os comandos destas instituições elaboraram um plano conjunto com a seguinte designação:"Plano de prevenção de suicídios nas forças de segurança"

Deste plano resultou:

-A criação de uma linha telefónica SOS comum às duas forças de segurança, que permita a identificação de situações de risco de suicídio e possibilite uma acção imediata nesse contexto.

- Reforço da avaliação dos traços de personalidade na selecção dos candidatos e proceder à sua reavaliação no final do curso e durante o primeiro ano de serviço.

-Ao nível da prevenção o Plano defende avaliações periódicas e aleatórias, relativas ao abuso de álcool e outras substâncias.

-Neste Plano é defendido a criação de procedimentos e normas de referenciação de doentes em risco para os gabinetes clínicos de psiquiatria e psicologia das duas forças.

-Prevê a restrição do uso da arma aos elementos a que forem identificados factores de vulnerabilidade psíquica que indiciem o risco de suicídio. Nestes casos é defendido que as funções do agente sejam redefinidas e forma a reduzir os factores de stress.

- Mas os resultados práticos deste plano não estão a surtir os efeitos desejados, para o autor deste trabalho a solução não está somente nestas medidas. As medidas deviam incidir:

- Facilitar a aproximação dos profissionais à família, até porque existem imensas casas da GNR próximas dos Postos Territoriais a serem utilizadas indevidamente (por quem menos precisa).

- Fazer uma avaliação pormenorizada à distribuição dos profissionais de forma a diminuir os profissionais da parte administrativa para assim reforçar os da parte operacional.

-Atendendo a que os militares dos Postos Territoriais são os mais expostos ao risco, devem de fazer uma alteração relativa aos subsídios que estão a ser atribuídos aos menos expostos.

- Alterar a escala de serviço para que cada profissional, possa estar dois dias por semana próximos da família.

- Alterar a forma promíscua como os profissionais das classes mais baixas hierarquicamente são tratados.

- Proporcionar aos mais carenciados os diversos apoios necessários.

- Incentivo ao exercício físico como forma de melhorar a condição física e mental.

-A atribuição das casas de veraneio deve ser feita atendendo não ao estatuto hierárquico mas sim relativamente ao rendimento e agregado familiar.

Atendendo a tudo o que foi descrito, falta somente mencionar as consequências do stress; este a longo prazo pode resultar nas seguintes condições físicas: alta tensão arterial, doenças contagiosas, problemas cardíacos, espasmos do cólon...A nível psicológico os seguintes sintomas: acidentes e lesões, comportamento suicida, abuso de substâncias e violência.

\section{Endereços electrónicos consultados}

www.gnr.pt

http://agency.osha.eu.int/publications/reports/stress www.forumtrasosmontes.com

www.osach.ca 